オレンジ川によるビニロン染色における内部吸着等温曲線

大阪府立大学工学部片山明・黒木宣产

応用化学教室小西謙三

\title{
THE INTERNAL ADSORPTION ISOTHERMS IN THE DYEING OF VINYLON WITH ORANGE II
}

By Akira Katayama, Nobuhiko Kuroki and Kenzō Konishi

(Dept. of Applied Chemistry, College of Engineering, University of Osaka Prefecture, Osaka, Japan.)

The equilibrium adsorption of Orange II by Vinylon has been investigated over a wide range of the dye concentration in the dyebath. The internal adsorption isotherms have been calculated from the results. They differ considerably from the linear form assumed in the formulation of the dyeing theory and far from a Langmuir or a Freundlich relation.

Taking into consideration a heterogeneity of the fibre, it has been assumed the Vinylon surface to be composed of three groups of dyeing sites having the different affinities for dye. The internal adsorption isotherms may be represented by the following equation-assuming a Langmuir adsorption of the dye on each group of dyeing sites-.

$$
[\mathrm{D}]_{\mathfrak{a}}=\frac{K_{1}[\mathrm{~S}]_{1}[\mathrm{D}]_{i n}}{1+K_{1}[\mathrm{D}]_{i n}}+\frac{K_{2}[\mathrm{~S}]_{2}[\mathrm{D}]_{\text {in }}}{1+K_{2}[\mathrm{D}]_{i n}}+K_{\mathbf{3}}[\mathrm{D}]_{\text {in }}
$$

The amount of dye adsorbed on the fibre surface was calculated using the equation (1). There was good agreement between the observed and the calculated values.

The saturation values [S] for each group of dyeing sites was independent of the concentration of salt in the dyebath but $K$ for each group considerably dependent of that.

The heat of dyeing for each group of dyeing sites was calculated. It was found that there were large differences in the heat of dyeing between the groups dyeing sites.

(Received September 29, 1961)

\section{I. 緒言}

現在の直接染料汇よるセルロース系紻維の染色の理論 は Hanson, Neale, Stringfellow らりの仮定に基礎学む゙

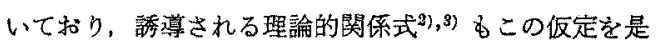
認して成り立つ8のである。

彼らは維維上に吸着された染料アニオン濃度 $[\mathrm{D}]_{a}$ と

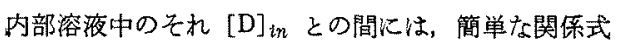

$$
[\mathrm{D}]_{a} /[\mathrm{D}]_{\mathrm{in}}=k
$$

が成立するものとし，この 関係に一定値を示し, 温度, 王力のみの関数であると纳 定した。

著者ら ${ }^{4), 5}$ は先比，ビ二ロン染色の際には $k$ の值は浴 中の電解質濃度にす依存することを指摘し，この依存性 は土として電解筫の脱水効果に上る染料分子の水和状態 の变化に基因するものと䓔えた。
本報では浴中の食塩濃度を一定とした場合，（1）の仮 定がとの程度成立しているかを調へる目的で，浴中染料 濃度のかなり㕕い範田沉わたる染着等温曲線を決定し， $[\mathrm{D}]_{a}$ と $[\mathrm{D}]_{m}$ の間の関係調べ，若干の考察を行なつ to

\section{II. 試料および実験方法}

用いたビニロン䋨，染浴に添加した食塩は前報4と同 様のるのである。

染料としては, 浴中の食塩および染料濃度による活量 係数の変化をできるだけ小さくするため、直接染科の使 用をさけ，簢単な模造を有するオレンジ五を選んた。

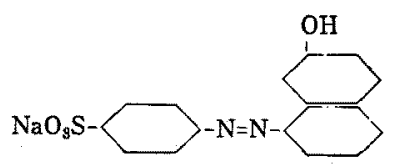


Meggy $\left.y^{6}\right)$ Kよれば，この染料証電解質濃度 $0.1 \mathrm{~mol} / l$ 纵下，温度 $60^{\circ} \mathrm{C}$ 以上の範囲では乞の活量係数沉はさし たる変化はないるのとされている。

染料の精製は，染料水溶液にボウ硝を加之て塩析する 操作を数回くり返し，沈でんを乾燥後エタ〉ールで染料 を抽出して無機物を分離し、水エタノール溶夜から再結 晶をすることによつて行なつた7)。

平衙染着量の測定方法结前報4),8) と同様である。

\section{III. 結 果}

ます⿺，1）染色温度: $70^{\circ} \mathrm{C}$, 浴中食塩濃度: $89.9 \mathrm{~m}$. $\mathrm{mol} / l, 2)$ 染色温度 : $80^{\circ} \mathrm{C}$, 浴中食塩濃度 $: 89.9 \mathrm{~m} . \mathrm{mol} / l$, 3)染色温度 : $70^{\circ} \mathrm{C}$, 浴中食塩濃度 : $.45 \mathrm{~m} . \mathrm{mol} / \mathrm{l}$ の場合について浴中染 料瀑度を $0.0139 \sim 13.8 \mathrm{~m} . \mathrm{mol} / \mathrm{l}$ の 蝺囲の染着等温曲線を決定した。

得られた結果を用い，以下の取り 报い炕よつて $[\mathrm{D}]_{a}$ および $[\mathrm{D}]_{\text {in }}$ を 算出した。用いた記号はすべて前報せ と同様てある。

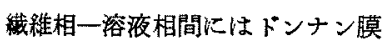
平衡が成立し，䋊維相扣よび容液相 の電気的中性を仮定すれば絾維相中 のナトリウムイオン濃度は Vicker:stafi”) の提出した式（2）によつて 試算することができる。

$$
\begin{aligned}
{[\mathrm{Na}]_{i n}=} & \frac{[\mathrm{D}]_{F}}{V}\left\{\frac{z}{2}+\left(\frac{z^{2}}{4}\right.\right. \\
& \left.\left.+\frac{[\mathrm{Na}]_{s} \cdot[\mathrm{Cl}]_{5} \cdot V^{2}}{[\mathrm{D}]_{F}^{2}}\right)^{1 / 2}\right\}
\end{aligned}
$$

また, 膜平衡の仮定により $[\mathrm{Na}]_{s}$,

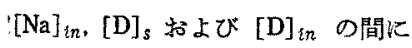
はつぎの上5な関保式

$$
\frac{[\mathrm{Na}]_{s}}{[\mathrm{Na}]_{i n}}=\left(\frac{[\mathrm{D}]_{\mathrm{in}}}{[\mathrm{D}]_{s}}\right)^{1 / z}=\lambda
$$

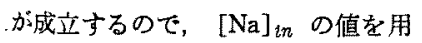
いて膜平衡定数 $\lambda$ の值を求め，つい でが [D] 敒を算出することができる。

$$
[\mathrm{D}]_{F} \text { はつぎのよ5に表わされる }
$$
.ので

$$
[\mathrm{D}]_{F}=[\mathrm{D}]_{a}+V[\mathrm{D}]_{i n}
$$

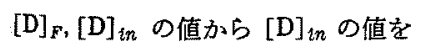
算出した。

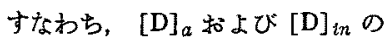

算出には，1）維相一溶液相間のドンナン膜平衡の成 立，2）㵶維相拈よび容夜相の電気的中性以外の仮定は 入つていない。

なお，䋐維相扣よび溶液相中の染料および食塩の活量 に関しては知られていないので上の取り报いにおいては 活量のかわりに濃度を用いた。

得られた結果は第 I 表a)，b) 挔よびc) 中に示した。

\section{IV. 考察}

第1表より明らかなよ 上および浴中の染料濃度が增すにつれて著しく減少する 傾向を示して和り，染料濃度のかなり広い範囲にわたつ

\begin{tabular}{|c|c|c|c|c|c|c|c|}
\hline$[\mathrm{D}]_{\mathrm{s}}$ & {$\left[\mathrm{D}_{F}\right]$} & {$[\mathrm{Na}]_{\text {in }}$} & $\lambda$ & {$[D)_{i n}$} & obs. & ]$_{a}$ calc. & $k$ \\
\hline 0.0142 & 0.217 & 90.5 & 0.994 & 0.0142 & 0.215 & 0.217 & 79.9 \\
\hline 0.0286 & 0.475 & 91.1 & 0.987 & 0.0282 & 0,470 & 0.421 & 87.7 \\
\hline 0.0431 & 0.587 & 91.5 & 0.983 & 0.0423 & 0.579 & 0.604 & 72.0 \\
\hline 0.0576 & 0.753 & 91.9 & 0.978 & 0.0563 & 0.742 & 0.781 & 69.3 \\
\hline 0.0866 & 1.01 & 92.6 & 0.971 & 0.0841 & 0.994 & 1.10 & 62.2 \\
\hline 0.145 & 1.57 & 94.2 & 0.954 & 0.140 & 1.54 & 1.66 & 58.7 \\
\hline 0.290 & 2.71 & 97.4 & 0.923 & 0.268 & 2. 66 & 2.70 & 52.3 \\
\hline 0.436 & 3.50 & 99.8 & 0.901 & 0.393 & 3. 43 & 3. 57 & 45.9 \\
\hline 0.582 & 4.17 & 102 & 0.883 & 0.541 & 4.07 & 4.22 & 41.6 \\
\hline 0.875 & 5. 40 & 106 & 0.851 & 0.745 & 5. 36 & 5.34 & 37.8 \\
\hline 1. 48 & 6.97 & 111 & 0.811 & 1.20 & 6.75 & 7.09 & 29.6 \\
\hline 2.95 & 9. 72 & 120 & 0.747 & 2. 21 & 9. 30 & 9.72 & 22.2 \\
\hline 4.43 & 11.8 & 128 & 0.701 & 3. 11 & 11.2 & 11.3 & 18.9 \\
\hline 5.91 & 13.6 & 135 & 0.665 & 3. 93 & 12.9 & 12.4 & 17.2 \\
\hline 8.86 & 15. 5 & 144 & 0.626 & 5.55 & 14.5 & 13.8 & 13.7 \\
\hline 3.3 & 16. 9 & 151 & 0. 579 & 7.93 & 15.4 & 15.2 & 10.2 \\
\hline
\end{tabular}
$[\mathrm{D}]_{s},[\mathrm{Na}]_{i n}$ and $[\mathrm{D}]_{i n}$ are in $\mathrm{m} . \mathrm{mol} / \mathrm{l} ;[\mathrm{D}]_{F}$ and $[\mathrm{D}]_{a}$ in $\mathrm{m.mol} / \mathrm{kg}$ a) $[\mathrm{Cl}]_{s}=89.9 \mathrm{~m} . \mathrm{mol} / \mathrm{l}$, temp $=70^{\circ} \mathrm{C}$

\begin{tabular}{cccccccc}
{$[\mathrm{D}]_{s}$} & {$[\mathrm{D}]_{F}$} & {$[\mathrm{Na}]_{i n}$} & \multicolumn{1}{c}{$\lambda$} & \multicolumn{1}{c}{$[\mathrm{D}]_{i n}$} & \multicolumn{2}{c}{$[\mathrm{Dbs}]_{a}$} & $k$ \\
0.0139 & 0.370 & 90.9 & 0.989 & 0.0137 & 0.367 & 0.377 & 141 \\
0.0282 & 0.669 & 91.7 & 0.980 & 0.0276 & 0.664 & 0.702 & 126 \\
0.0426 & 0.950 & 92.5 & 0.972 & 0.0414 & 0.942 & 1.00 & 120 \\
0.0568 & 1.18 & 93.1 & 0.966 & 0.0549 & 1.17 & 1.23 & 113 \\
0.0856 & 1.58 & 94.2 & 0.954 & 0.0817 & 1.57 & 1.65 & 101 \\
0.141 & 2.33 & 96.1 & 0.935 & 0.132 & 2.31 & 2.30 & 92.0 \\
0.289 & 3.65 & 99.9 & 0.900 & 0.260 & 3.60 & 3.57 & 72.9 \\
0.434 & 4.77 & 103 & 0.872 & 0.378 & 4.70 & 4.50 & 65.5 \\
0.581 & 5.47 & 105 & 0.855 & 0.496 & 5.38 & 5.32 & 57.1 \\
0.873 & 6.85 & 109 & 0.824 & 0.719 & 6.71 & 6.66 & 49.0 \\
1.48 & 9.05 & 116 & 0.777 & 1.15 & 8.83 & 8.76 & 40.5 \\
2.95 & 13.2 & 128 & 0.700 & 2.07 & 12.8 & 12.2 & 32.6 \\
4.43 & 15.2 & 134 & 0.672 & 2.98 & 14.6 & 14.6 & 25.7 \\
5.91 & 16.9 & 139 & 0.649 & 3.83 & 16.2 & 16.6 & 22.3 \\
8.86 & 19.9 & 146 & 0.616 & 5.46 & 18.9 & 19.8 & 18.2 \\
13.3 & 22.3 & 148 & 0.606 & 8.05 & 20.8 & 24.8 & 13.6
\end{tabular}

b) $[\mathrm{Cl}]_{s}=89.9 \mathrm{~m} . \mathrm{mol} / \mathrm{l}, \quad$ temp $=80^{\circ} \mathrm{C}$ 
c) $\mathrm{NaCl}=45.0 \mathrm{~m} \cdot \mathrm{mol} / \mathrm{l}$, temp $=70^{\circ} \mathrm{C}$

\begin{tabular}{|c|c|c|c|c|c|c|c|}
\hline$[D]_{s}$ & {$[\mathrm{D}]_{F}$} & {$[\mathrm{Na}]_{i n}$} & $\lambda$ & {$[\mathrm{D}]_{k n}$} & obs. & ]$_{a}$ calc. & $k$ \\
\hline 0.0142 & 0.205 & 45.6 & 0.988 & 0.0140 & 0.202 & 0.227 & 75.8 \\
\hline 0.0287 & 0.374 & 46.0 & 0.978 & 0.0281 & 0.369 & 0.442 & 69.1 \\
\hline 0.0432 & 0.520 & 46.4 & 0.970 & 0.0419 & 0.512 & 0.638 & 64.3 \\
\hline 0.0576 & 0.682 & 46.8 & 0.962 & 0.0554 & 0.672 & 0.820 & 63.8 \\
\hline 0.0866 & 0.973 & 47.7 & 0.943 & 0.0817 & 0.958 & 1. 15 & 61.7 \\
\hline 0.145 & 1. 43 & 49.0 & 0.918 & 0.133 & 1.41 & 1. 71 & 55.8 \\
\hline 0.291 & 2.61 & 52.5 & 0.857 & 0.249 & 2.56 & 2.74 & 54.1 \\
\hline 0.437 & 3.23 & 54.5 & 0.826 & 0.361 & 3.16 & 3.53 & 46.1 \\
\hline 0.584 & 3.84 & 56.5 & 0.796 & 0.465 & 3. 75 & 4. 15 & 42.4 \\
\hline 0.877 & 4.83 & 59.9 & 0.751 & 0.659 & 4. 70 & 5. 22 & 37.5 \\
\hline 1. 47 & 6.64 & 66.4 & 0.678 & 0.999 & 6. 45 & 6.43 & 34.0 \\
\hline 2. 95 & 8. 47 & 73.8 & 0.610 & 1.80 & 8. 13 & 8.46 & 23.7 \\
\hline 4. 43 & 9.60 & 78.7 & 0.572 & 2.54 & 9. 12 & 9.65 & 18.9 \\
\hline 5.91 & 10.6 & 83.3 & 0.540 & 3. 19 & 10.0 & 10.4 & 16.5 \\
\hline 8.86 & 12.8 & 93.3 & 0.482 & 4. 27 & 12.0 & 11.3 & 14.8 \\
\hline 3.3 & 13.8 & 99.1 & 0.454 & 6.03 & 12.6 & 12. 2 & 11.0 \\
\hline
\end{tabular}

いないのて $[D]_{\text {in }}$ [D $]_{a}$ の間に Langmuir 型吸着を仮定することに は無理が步る。

Holmes $^{11)}$ はクリソフェニン GK よるモメン染色の際の内部吸着を詳 細に研究し，その吸着等温曲線性 Freundlich 式で近似し得るすのと している。

第 2 図に第 1 表a),b) の結果汇つ いての $\log [\mathrm{D}]_{a} の \log [\mathrm{D}]_{\text {in }}$ 対す るプロットを示したが，いずれの場 合にも直線からのずれはかなり著し く,得られた吸着等温曲線をFreundlich 式をつて近似することは因難 である。

Holmes ${ }^{11}$ ) は実験結果の理論から のずれはもつぱら活墨係数の無視によるものとしている が，先にも述へたよ5に染科濃度のきわめて5すい範团

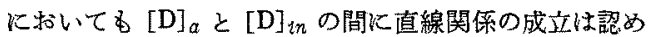
られず，本実験に拈ける理墖からの背遧を活量係数の立 場のみから説明することは困難であり，活量係数以外の 因子をも考慮する必要があるものと考えられる。

第 1 亿考学るべきは㵶維の不均一性である。染色理論 に拈いては，織維の均一性が瞕暗の中に仮定されている が，㵶維が全く均一であると仮定することは本質的には 正しくないし，この仮定は検討を要する。

著者ら ${ }^{12)}$ は先に無塩の場合の直接染料によるピニロン の染色について報告し，ビニロン中には活性度の異なる 少くとも2 種類以上の染着座席が存在しているする考 えた。本実駼の場合汇も活性度の異なる染着坐席の存在 を仮定して以下の取り扱いを行なつた。

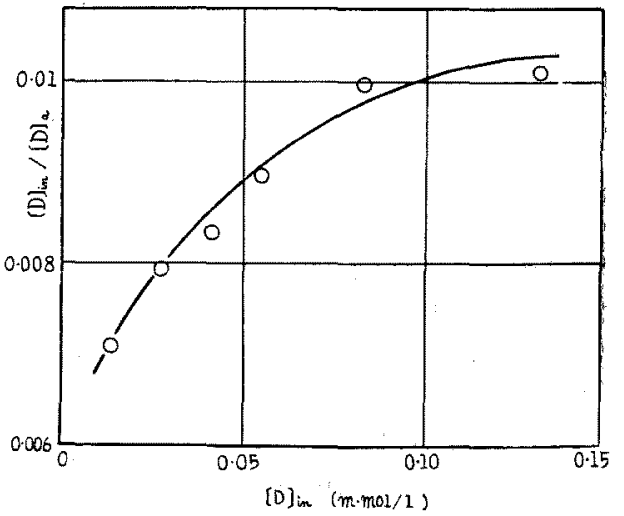

Fig. 1. The relation between $[D]_{i n} /[D]_{a}$ and $\left[D_{i n}\right]$ $\mathrm{NaCl}=89.9 \mathrm{~m} . \mathrm{mol} / l$, temp $=70^{\circ} \mathrm{C}$. 


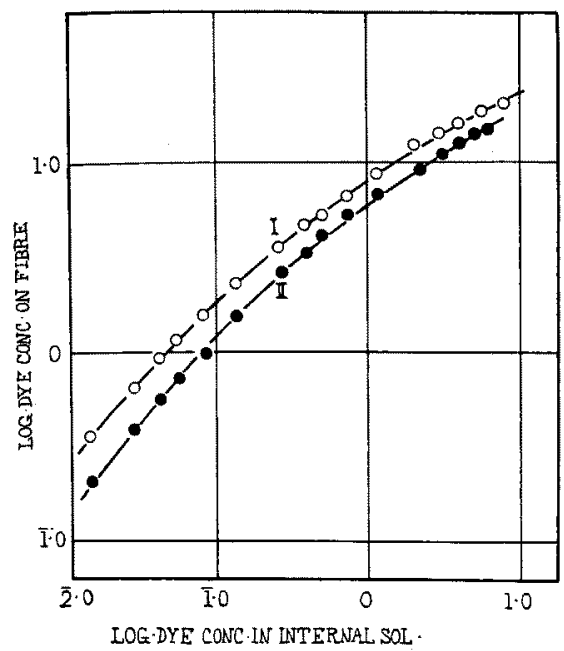

Fig. 2. The relations between $\log [D]_{a}$ and $\log [D]_{i n}$. I : $\mathrm{NaCl}=89.9 \mathrm{~m} . \mathrm{mol} / l, \quad$ Temp $=70^{\circ} \mathrm{C}$ II $: \mathrm{NaCl}=89.9 \mathrm{~m} . \mathrm{mol} / l, \quad$ Temp $=80^{\circ} \mathrm{C}$

ます，内部浴液から瀻維上への染料の吸着は， Langmuir 式に従 5 わのとし， 3 種類の染着座席の存在を仮 定すると，緎維上の染料濃度 $[\mathrm{D}]_{a}$ は次式で表方され ל。

$$
[\mathrm{D}]_{a}=\frac{K_{1}\left[\mathrm{~S}_{1}\right][\mathrm{D}]_{i n}}{1+K_{1}[\mathrm{D}]_{i n}}+\frac{K_{2}\left[\mathrm{~S}_{2}\right][\mathrm{D}]_{i n}}{1+K_{2}[\mathrm{D}]_{i n}}+K_{3}[\mathrm{D}]_{i n}
$$

(7)式の右辺第 3 項は Langmuir 型吸着の初期部分 に対応させるためのるのである。

実験結果を(7)式に適用して算出した各染着座席に対 応する $K$ および［S］の值を第 2 表に示した。

Table. II.

\begin{tabular}{|c|c|c|c|c|c|c|}
\hline Dyeing site & \multicolumn{2}{|c|}{ I } & \multicolumn{2}{|c|}{ II } & \multicolumn{2}{|c|}{ III } \\
\hline Dyeing condition & $K_{1}$ & $S_{1}$ & $K_{2}$ & $S_{2}$ & $K_{3}$ & $S_{3}$ \\
\hline $\begin{array}{l}\text { Temp }=70{ }^{\circ} \mathrm{C} \\
\mathrm{NaCl}=89.9 \mathrm{~m} . \mathrm{mol} / l\end{array}$ & 9.75 & 2.25 & 0.46 & 15. 4 & 1.2 & - \\
\hline $\begin{array}{l}\text { Temp }=80^{\circ} \mathrm{C} \\
\mathrm{NaCl}=89.9\end{array}$ & 4.56 & & & 7.8 & - & - \\
\hline $\begin{array}{l}\text { Temp }=70^{\circ} \mathrm{C} \\
\mathrm{NaCl}=45\end{array}$ & 4.09 & & & 3.0 & - & - \\
\hline
\end{tabular}

なお，染着座席且に対応する $K_{3}$ 口檤は，染色温度： $80^{\circ} \mathrm{C}$, 浴中食塩濃度 $: 89.9 \mathrm{~m} . \mathrm{mol} / l$, 扣よび染色温度： $70^{\circ} \mathrm{C}$, 浴中食塩溽度 : $45 \mathrm{~m} . \mathrm{mol} / l$ の 2 つの条件下では 縤維上に吸着される染料濃度範两が十分でなく，（7)式 適用して算出することができなかつたのて $K_{3}$ の奇与 苍無視して $K_{1}, K_{2}, S_{1}$ 招よび $S_{2}$ の值を算出した。

（7）式と第 2 表の $K$ 挔よびSの値を用いて計算した
[D] $]_{a}$ の值を第 1 表中に示したが，い声れの染色条件に 招いても計算值と寒測值の一致はかなり良好であり，内 部吸着等温線は近似的には（7）式で表わすことが可能 であるものと考えられる。すなわち，本策験代用いた染 料濃度籁因では最低 3 種類の染着四席の存在を仮定する ことによつて実験結果を満足に説明することができる。

第 2 表上りすれば，染着座席 I の飽和值は $2.3 \mathrm{~m} . \mathrm{mol} /$ $\mathrm{kg}$, 染着夾席开の々れは $15 \mathrm{~m} . \mathrm{mol} / \mathrm{kg}$ 程度でるる。染 色条件によつて，得られた值にはかなりのばらつきを生 ずるが，いすれの場合比大体一定值が得られることは

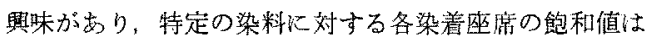
染色条件に上つては影諳されないるのと推察される。し かし，染料の種類が異なれば各染着座席に対する飽和值 の値も異なり，なた飽和値と染料の分子罣の間心る明確 な関倸は認められない（詳細は後に報告する）ので，飽 和檤の具体的意味ずけは困難である。

第3図に第 1 表 a) の場合の各染着座席に詨する内部 吸着等温曲線を，第 4 図汇瀻維上の種々の染料濃度にお。 ける，各染着座席に吸着されている染料の分布を示し た。

$70^{\circ}$ と $80^{\circ}$ に括汁る結果を用い

$$
\Delta H^{\circ}=\frac{R T_{1} T_{2}}{\left(T_{2}-T_{1}\right)} \ln -[\mathrm{D}]_{s_{2}}
$$

（8）式によつて染着座席 I およびII 亿対する染色熱を 計算してみるとそれぞれー20 kcal/mol 拈よび - $2 \mathrm{kcal}$ / mol 程度である。得られた数值そのるのにはあまり信頼 性はないが，染着來席Ｉ怙よびの間には非常に大きな 活性度の相違のあることを示す炕分である5。

著者ら ${ }^{12)}$ は先にクリソフェニンNSでビニロンを染色 した際，その染色熱は綪維中の染料濃度に関係し，染料 濃度の減少々ともに染色熱は大となることを報告し，そ の原因はビニロン中に活性度の異なる染着座席が存在す ることによるものとした。各染着座席上への染料の分布 が第 4 図のような形をとる場合，䋐維上の染料濃度の普 加とともに染色熱功減少することは容易に理解される。 すなわり，第 4 図より明らかなよらに，染色熱の大きい 染着座席 I に吸着されている染料の全染着量に対寸る割 合は䋐維上の染料濃度の増加とともに急激に減少する。 一方，染色熱の小さい染着座席上に吸着されている染料 の割合は繊維上の染料濃度の增加とともに增大してゆ く。実測される染色熱はこれら各染着座帛に刘するもの の平均であるのて，䄉維上の染料澧度の增加とともに染 色熱は減少するるのと荐えられる。

また，浴中食塩濃度はドンナン膜平衝の関保に従つて 内部溶液中の染料濃度る規定するのみでなく，内部平衡 にも影響を特よ注していることは第 2 表より明らかであ 


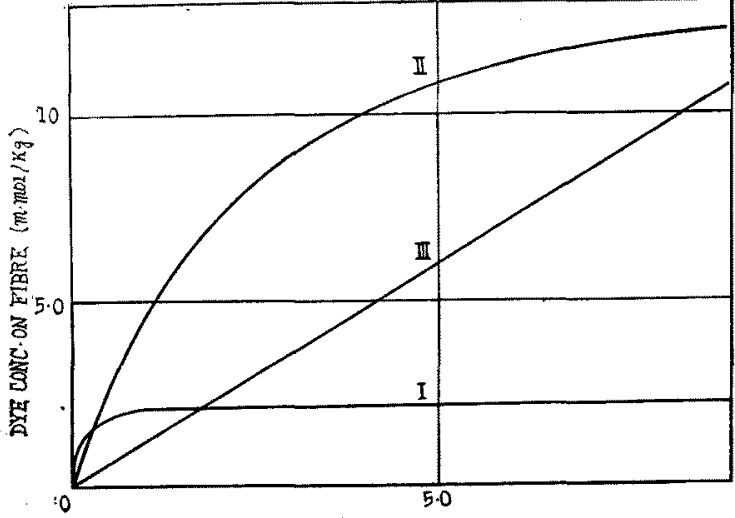

DYE CONC IN INTERNAL SOL. (m.moI/ $/$ ).

Fig. 3. Internal adsorption isotherms for dyeing site I, II and III. dyeing temp $=70^{\circ} \mathrm{C}, \mathrm{NaCl}=89.9 \mathrm{~m} . \mathrm{mol} / \mathrm{l}$

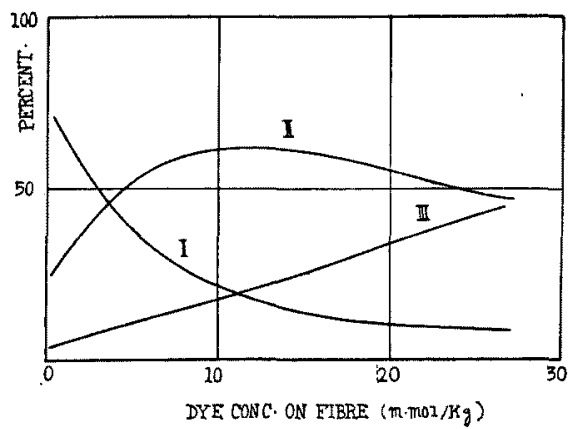

Fig. 4. Distribution of adsorbed dye on each dyeing site at various dye concentration on fibre.

る。すなわち，染色温度 $70^{\circ} \mathrm{C}$, 浴中の食塩濃度が 89.9 m. mol/l wよび $45 \mathrm{~m} . \mathrm{mol} / l$ の場合に得られた $K_{1}$ の值 を比較してみると浴中塩濃度の增大は $K_{1}$ の值を影著に 増大させる作用のあることが認められる。この際， $K_{2}$ の值は食塩濃度の低い場合の方がわずが大とななつて いるが，これは浴中食塩潭度が $45 \mathrm{~m} . \mathrm{mol} / l$ の場合は先 にも述べたよ 5 K実験データから $K_{3}$ の值を決定するこ とがでさないのでこの項の寄与杂無視したため， $K_{2} の$ 值が不当に大きく見積られている結果と考えられる。

以上, ビニロンの不均一性を考虑して，得られた内部
昅着等温曲線の結果の説明圶試みたが，3種類 の染着座席の存在を仮定すれば大体満足に搃明 し得るるのと考えられる。またこのような結 果からすれば一般に行なわれている方法で計算 した親和力, 染色熱括よび染色のエントロピー 変化の值核平均值的な意味を有するに過ぎない が，染浴浀度の類似した籁团内で染料間の比敦 を行ならときにはその染色挙動を示す大体の目 安とはなり得るものと考えられる。

\section{䬥括}

染浴漊度の広い簌国にわたつて内部吸着等温 曲線を調べた結果

1) $[D]_{a}$ と $[D]_{\text {in }}$ の間には直線関係は成立 せずまた吸着は Freundlich, Langmuir い ずれの型にも従わない。

2）ビニロン中に 3 種類の染着座席が存在し，それら に対する染料の吸着がそれぞれ Langmuir 型であると 仮定すれば，得られた結果を満足火説明することができ る。

3) 染着座席IのオレンジIIに対する染色熱は -20 $\mathrm{kcal} / \mathrm{mol}$, 染着座席开のそれは $-2 \mathrm{kcal} / \mathrm{mol}$ 程度と推 定される。

ビニロンを提供していたたいた倉敖レイヨン K.K.に 感謝する。

\section{文献}

1) Hanson, Neale, Stringfellow ; Trans. Faraday Soc., 31, 1718 (1935)

2) Standing ; J. Text. Inst., 45, T 21 (1954)

3) Standing, Warwicker ; J. Text. Inst., 40, T 175 (1949)

4) 片山，黒木，小西；裁学誌，15，1007 (1959)

5) 片山，黒木, 小西；織学誌，18，356（1962）

6) Meggy ; Trans. Faraday Soc., Discussions, No. 16, 149 (1954)

7) 安蕌; “染料琹質学”

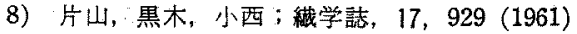

9) Peters, Vickeıstaff ; Proc. Roy. Soc., A 192, 292 (1948)

10) Crank ; J.Soc. Dyer Col., 63, 293 (1947)

11) Holmes; Trans. Faraday Soc., 54, 1172 (1958)

12) 片山，黑不，小西；䋐学誌，15，1011（1959） 